\title{
IMPACT OF OCCUPATIONAL SOCIALIZATION ON THE PERSPECTIVES AND PRACTICES OF SPORT PEDAGOGY DOCTORAL STUDENTS
}

\author{
by \\ HONG-MIN LEE
}

\begin{abstract}
A THESIS
Submitted in partial fulfillment of the requirements

for the degree of Master of Arts in Kinesiology in the Graduate School of

The University of Alabama
\end{abstract}

TUSCALOOSA, ALABAMA 
Copyright Hong-Min Lee 2010

ALL RIGHTS RESERVED 


\begin{abstract}
The theoretical framework of occupational socialization has been used to good effect to explain why preservice and inservice physical education (PE) teachers think and teach as they do. The purpose of this study was to use the same lens to examine the perspectives and practices of a cohort of sport pedagogy doctoral students in terms of PE teaching and physical education teacher education (PETE). Participants were 12 doctoral students enrolled in one university's sport pedagogy doctoral program. Data were collected through formal and informal interviews, observations, and self-reflective posters. They were analyzed using analytic induction and constant comparison. Key findings were that doctoral students espoused both conservative and liberal forms of PE and PETE and that these views were shaped by the interaction of the various phases of their socialization. Doctoral students recalled being oriented to both teaching and coaching. The longer coaching orientations remained intact the more likely they were to espouse conservative versions of PE and PETE. Prior to their graduate work, the pattern of socialization for the cohort of students was similar to that illustrated in other studies. What was new, however, was the power and potency of the students' graduate education or secondary professional socialization. This appeared to be primarily due to influential faculty, a practitioner focus in master's degree programs, and engagement in undergraduate PETE.
\end{abstract}




\section{ACKNOWLEDGMENTS}

I would like to extend my sincere appreciation and gratitude to Dr. Matthew CurtnerSmith, chairperson of my thesis committee and academic advisor, whose direction, encouragement, and guidance served as an inspiration to me not only in this study but throughout my graduate program. I would also like to express my appreciation to Dr. Jim Siders and Dr. Oleg Sinelnikov for the assistance they provided as members of my thesis committee. Also, I am grateful to all of the participants in my study.

Most importantly, I would like to express my love and gratitude to my parents, Ki-Yong Lee and Seok-Bun Yang, for their unending love, support, and encouragement, but most of all for the value of life they taught to me through the years. I am deeply grateful to them for the example they set for me. It is to them that I dedicate this work. 


\section{CONTENTS}

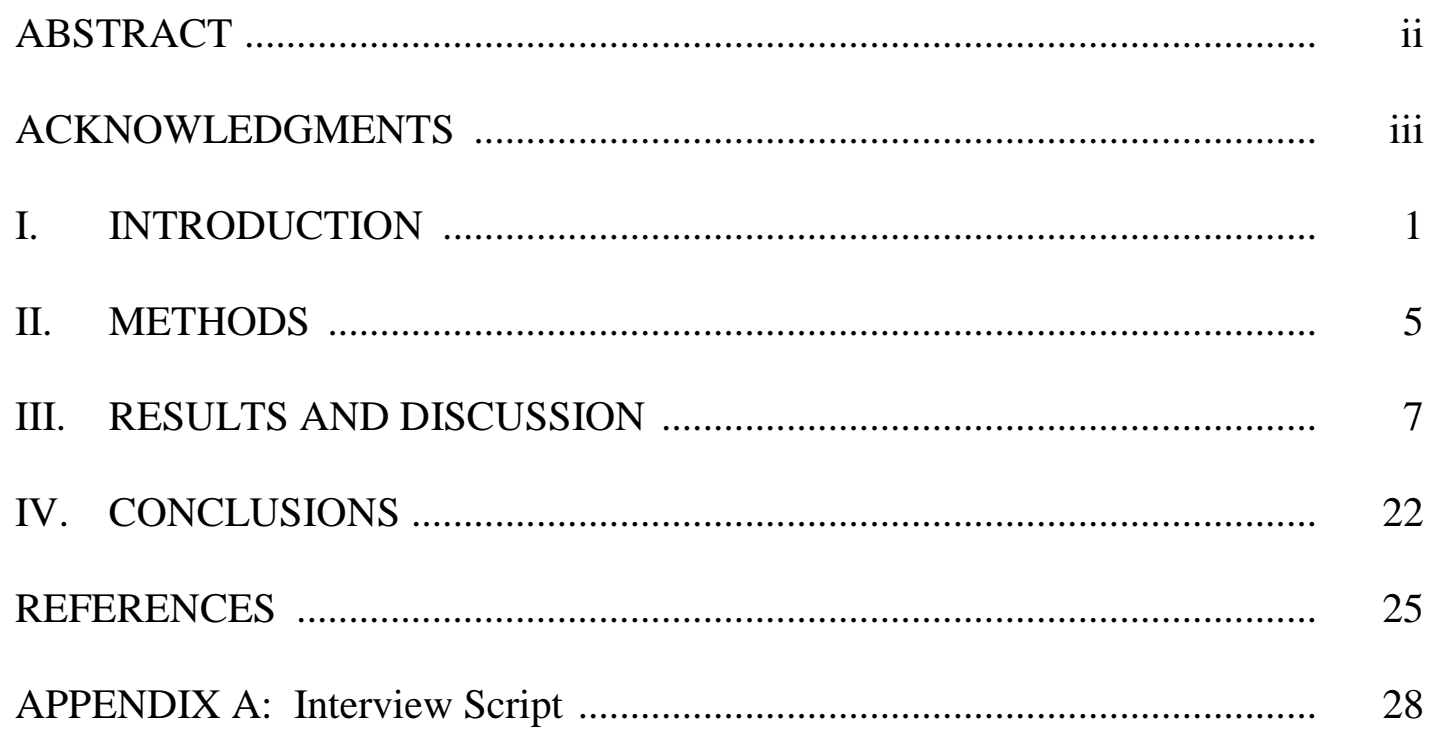




\section{CHAPTER I}

\section{INTRODUCTION}

The theoretical framework of occupational socialization has been used to good effect to explain why preservice and inservice physical education (PE) teachers think and teach as they do (Curtner-Smith, 2001, 2009; Curtner-Smith, Hastie, \& Kinchin, 2008; Lawson, 1983a, 1983b; Schempp \& Graber, 1992; Stroot, 1993; Templin \& Schempp, 1989). Researchers working in this area have focused on teachers' acculturation, professional socialization, and organizational socialization.

Acculturation is the most powerful form of socialization PE teachers experience. It can begin at birth through the nurturing of a sporting interest by parents and siblings which, in turn, leads to an interest in PE. This interest can be further developed during the "apprenticeship of observation" (Lortie, 1975) when prospective teachers' views about the subject are molded by their interactions with PE teachers and extracurricular sport coaches.

In his seminal work, Lawson $(1983 a, 1983 b)$ theorized that two very different kinds of recruit were produced by the acculturation process and entered PE teacher education (PETE). For one kind of recruit PE teaching was a "career contingency." Instead, the focus was on coaching extracurricular sport. Coaching-oriented recruits were more likely to have played a high level of a traditional school sport, attended schools at which this sport was given priority over PE, and be male. Recruits committed to a very high sporting level were likely to reject the values and practices espoused within high-quality PETE. Moreover, the impact of high-quality PETE on 
talented but not fully committed sportsmen and women was likely only to be minimal. For the second kind of recruit, coaching extracurricular sport was a career contingency. The main focus was on PE teaching. Teaching-oriented recruits were more likely to have participated in nontraditional sport or non-competitive physical activities, attended schools which prioritized good quality PE over extracurricular sport, and be female. These recruits were also more likely to enthusiastically accept the practices and beliefs espoused in quality PETE programs.

Professional socialization refers to the impact of PETE on preservice teachers (PTs). In general, research has shown PETE to have a relatively low impact on many PTs. Rather than change misguided views about PE and pedagogy with which many PTs enter their PETE programs with, many programs appear to support these views. Those programs that do succeed in changing flawed beliefs and practices are usually run by innovatively oriented, non-coaching, highly credible, specialist sport pedagogy faculty. These teacher educators usually supervise and monitor early field experiences (EFEs) and student teaching vigorously. Moreover, they generally come to a consensus on what Lortie (1975) described as a "shared technical culture" (i.e., the knowledge and practices crucial for effective PE teaching) and about their program's professional ideology.

Organizational socialization refers to the impact of the school culture on inservice teachers from the time they take their first position. Essentially, it is the process by which one generation of teachers passes its beliefs, practices, and protocols on to the next. For this reason, Lawson (1983a, 1983b) suggested that beginning PE teachers who entered the workforce with innovative teaching orientations to their subject were likely to clash with the existing culture. Despite the misery this state of affairs was likely to cause, Lawson (1983a, 1983b) also theorized that innovatively oriented PE teachers would make every effort to use effective practice even when faced with severe opposition. Zeichner and Tabachnik (1981,1983), however, warned that this kind of 
socialization could be particularly conservative and described it as an "institutional press" which often served to "wash out" any new ideas and practices which neophyte teachers had learned during their teacher education programs. According to Etheridge (1989), washout began when beginning teachers lowered their standards in order to fit in. Although teachers' original intent was for this period of "strategic adjustment" to be short-term, eventually it became permanent. In congruence, Lacey (1977) suggested that some beginning teachers with innovative orientations would try to "strategically redefine" poor-quality programs by advocating and employing new ideas and practice. Conversely, others would "strategically comply" with these poor programs when being observed by or working alongside senior colleagues so as to survive. When not being observed and working alone, however, they would use the innovative practices in which they really believed.

Extrapolating from Van Maanen and Schein's (1979) work on socialization tactics, Lawson (1983a, 1983b) also theorized that innovatively oriented beginning PE teachers who gained employment in schools in which their socialization was serial (being mentored), collective (with other beginning teachers), variable (without specific deadlines), sequential (followed a predictable order), and involved divestiture (innovative beliefs and pedagogies were rejected) were likely to be forced to strategically comply with the more experienced teachers in their departments. By contrast, innovatively oriented beginning PE teachers who landed jobs in schools in which their socialization was informal, disjunctive (they were not mentored), individual (by themselves), random (did not follow a predictable order), and involved investiture (innovative beliefs and pedagogies were supported and encouraged) were likely to teach in line with their PETE.

Conversely, Lawson (1983a, 1983b) argued that beginning teachers with conservative coaching orientations who had either had their orientations reinforced by low-quality PETE or 
been unaffected by high-quality PETE were very unlikely to attempt to use new and innovative pedagogies at all. Moreover, they would oppose high-quality school PE programs and support those programs which were of low quality.

\section{Purpose}

While a good deal of research has been conducted on the effects of occupational socialization on preservice and inservice teachers and some research has been conducted on professors of sport pedagogy (e.g., Goc Karp \& Williamson, 1993; Graber, 1993; Mitchell, 1993), little research of this type has been conducted on those learning to train teachers. The purpose of this study, therefore, was to examine the impact of occupational socialization on the perspectives and practices of a cohort of sport pedagogy doctoral students in terms of PE teaching and PETE. The main goal was to examine the effects and interactions of and between the participants' acculturation, initial professional socialization (i.e., undergraduate PETE), organizational socialization, and secondary professional socialization (i.e., graduate work in sport pedagogy). 


\section{CHAPTER II}

\section{METHODS}

\section{Participants}

The participants in this study were 12 sport pedagogy doctoral students learning to train teachers and do research on PE teaching, teacher education, teachers, and curriculum at one southeastern university in the United States. Four participants were male and eight were female. Nine were Caucasian, one was African-American, one was Asian, and one was African. Seven of the participants were graduate teaching assistants. One participant was in her first year of study, five were in their second year, and six had more than 2 years in their respective programs. The students ranged in age from 26 to 55 years.

\section{Data Collection}

All participants were interviewed formally. Formal interviews were designed to gather relevant background information and data on the participants' acculturation, initial professional socialization (i.e., undergraduate PETE), organizational socialization, and secondary professional socialization in graduate school. In addition, participants were asked about their past and current perspectives and practices on PE teaching and PETE. Each interview was approximately 45 to 60 minutes in duration and was audiotaped and transcribed verbatim. The script for the formal interview (see Appendix A) and the protocol by which it was carried out was semi-structured (Patton, 1990). It was largely based on an interview script used in earlier work conducted by Curtner-Smith et al. (2008). The same set of primary questions was posed to all participants. 
Once participants had provided their initial answers, the protocol allowed for multiple follow-up questions and prompts.

Whenever the opportunity presented itself, the researcher also informally interviewed participants with the aim of gathering fresh and relevant data or clarifying and confirming data that had been collected previously. Participants were also observed teaching physical activity courses within the university Basic PE Program (BPEP), teaching children in schools, supervising student teachers, and teaching methods courses for undergraduate PTs. During these observations, copious field notes were taken. Finally, seven participants produced a selfreflective poster in which they outlined key elements of their socialization into PE teaching and PETE.

\section{Data Analysis}

The first phase of analysis involved sorting data into those which described the participants' demographic backgrounds, acculturation, initial professional socialization, organizational socialization, and secondary professional socialization as well as their perspectives and practices in terms of teaching PE and doing PETE. During the second phase, analytic induction and constant comparison (Goetz \& LeCompte, 1984) were employed to code and categorize data with the goal of providing an interpretation on the relative effects of the various components of occupational socialization on the participants. Triangulation through the use of four data collection techniques and a thorough search for negative and discrepant cases (Goetz \& LeCompte) established trustworthiness. 


\section{CHAPTER III}

\section{RESULTS AND DISCUSSION}

\section{Current Perspectives on Teaching PE and Pedagogical Practices}

At the time the study was conducted, all 12 of the participants appeared to possess teaching orientations and, as illustrated by the following data extracts, were committed to their pupils' learning and viewed coaching extracurricular sport as of secondary importance to their main role:

As I made my way through the PETE program ... I realized that I had more of a teaching orientation. . . . I think I realized that teaching was more important than coaching. ... I just remember being excited and having high energy when I started my job. I wanted to go in and try to do the right things that I had learned in my PETE program. (Isabella ${ }^{1}$, formal interview)

Childhood obesity is just exploding. I want to help with that. I also want to teach children who are maybe not the most athletic, the ones who sit in the corner that don't play sports. I want them to feel included in the PE program because, a lot of times, it's just the kids who play sports ... that are really gifted as athletes that really get a lot out of PE. I want to help everybody. (Olivia, formal interview)

All 12 of the participants were also observed employing "effective teaching behaviors" (see Graham \& Heimerer, 1981; Silverman, 1991). For example, they provided a good deal of "performance feedback," "motivational feedback," and "engaged skill learning time." They provided "warm and welcoming classroom environments" and established good "managerial systems" in terms of "rules, routines, and expectations."

\footnotetext{
${ }^{1}$ The names of all individuals in this paper are fictitious.
} 
While their orientations and basic teaching skills were similar, however, the participants' goals and broad pedagogies differed significantly. Specifically, seven of the participants were much more conservative and traditional and indicated that they were aligned to the disciplinary mastery perspective (Jewett, 1994) on PE teaching. Consequently, they focused almost exclusively on their pupils' motor skill acquisition, used a narrow range of direct teaching styles, and employed well-executed versions of the multi-activity curriculum model to teach units on a variety of "different types of games," sports, and physical activities:

We're teaching fundamental skills and sport-specific skills.... We have a basketball court, a track, and a soccer field. We also have a volleyball court, so the students learn different types of games every term or semester. (Joshua, formal interview)

I could teach the way I wanted to and I kind of taught the way that my university taught, which was multi-activities. ... The department's main goals were to teach physical skills. ... to teach the rules of the game. I had put together a book. There were books for various rules of volleyball and basketball. (Ethan, formal interview)

Conversely, the other five participants were much more liberal and progressive in terms of their goals and broad pedagogies. Their teaching was driven by a variety of different value orientations including the disciplinary mastery, learning process, self-actualization, social reconstruction, and social responsibility orientations (see Jewett, 1994). Consequently, they were also interested in realizing cognitive, personal, and sociocultural objectives as well as the standard physical goals of motor skill learning and health and fitness. These perspectives, in turn, led to them employing a range of "direct and indirect teaching styles" and a variety of "different curriculum models" including the "multi-activity," "sport education," "games for understanding," and "health-related fitness" models.

There have been studies done where over 50 percent of the population of people with disabilities are obese. ... I saw the need for people with disabilities to be given opportunities to be physically active. . . I I want to be able to provide these opportunities for people with disabilities. (Ava, formal interview) 
I had all the input on various curriculum models.... The obesity problem is a big issue in the United States. . . I I thought the only way I could impact the problem other than talking to kids ... was teaching kids in the classroom. Physical education was a natural place to tell kids and show kids what sports, physical activity, and just being active can be and how important it is to your body and your life. (Michael, formal interview)

My goal was to give equal opportunity to girls to participate in sports. My physical education experiences were negative. Even though I played, my relationship with my PE teacher was not good. I didn't want girls to experience what I had experienced. (Sophia, formal interview)

I used the sport education model in my lessons.... Sport education is based on indirect teaching styles so students have more responsibilities and opportunities. ... Students could develop positive social skills. (Isabella, formal interview)

\section{Current Perspectives on PETE}

All of the participants endorsed an orientation to PETE that was primarily behavioristic (Zeichner, 1983) in nature. That is, they believed that prospective teachers were best trained through a series of methods courses, content courses, and field experiences during which they learned and were held accountable for demonstrating effective teaching behaviors, teaching styles, and the understanding and mastery of various curriculum models. Typical of comments alluding to this orientation in a positive light were the following:

PTs should be exposed to different physical education curriculum models and then PTs should practice in the schools so that they can broaden their pedagogical content knowledge. ... EFEs should be supervised by specialists. . . . Mosston's teaching styles and effective teaching behaviors are useful tools to teach students. These need to be covered during the PETE program. (Jacob, informal interview)

I believe that the PETE program should include content courses and extensive practical experiences in public schools.... Coursework should be integrated with student teaching experiences so students can practice the theory throughout methods courses in school settings. (Michael, informal interview)

There was no allusion to Zeichner's (1983) personalistic orientation to teacher education in which the goal of coursework is to develop psychological maturity. Four doctoral students, however, also appeared to believe fairly strongly that elements of the traditional/craft orientation 
(Zeichner) should be employed by teacher educators. Specifically, they were adamant that placing PTs with cooperating teachers who modeled good practice during field experiences was crucial to producing good teachers:

Potentially, cooperating teachers influence PTs professionally by changing the way they teach and view students. . . Teacher educators should show how to be effective physical education teachers who do not just go through the motions, but who really have a passion for the profession and strive to do the right things in the physical education setting. (Isabella, formal interview)

Similarly, three participants suggested that while teacher educators' main orientation should be behavioristic, the fourth of Zeichner's (1983) orientations, the critical-inquiry orientation, should also influence their practice. Like others before them (e.g., see Curtner-Smith, 2007; CurtnerSmith \& Sofo, 2004; Fernandez-Balboa, 1997), their motivation was to produce thinking teachers who examined their pedagogies for inequities, were interested in more than technical expertise, and considered political, social, moral, and ethical issues:

Low-skilled students are usually marginalized in PE classes... . The PETE program needs to include strategies that encourage low-skilled students to participate in the class actively, thus marginalized students are allowed the same opportunities as high-skilled students. (Ava, informal interview)

Finally, those doctoral students whose goals and pedagogies were more traditional and driven by the disciplinary mastery value perspective were also much more likely to support a more conservative form of teacher education and favor the behavioristic and traditional/craft orientations to PETE. Conversely, those participants with more progressive teaching orientations and whose goals and pedagogies reflected a broader variety of value orientations were more likely to favor a comparatively liberal version of teacher education and at least entertain the idea of including a critical element within PETE. 
Factors Influencing Doctoral Students' Perspectives

on Teaching PE and PETE and Pedagogical Practices

\section{Acculturation}

Early career choice. In line with most previous research of PE teachers' occupational socialization, all of the participants' in the current study indicated that they had initially become interested in a career in PE due to their enjoyment of "being active," and their "love of sport." As illustrated by the following data excerpts, this interest in sport and physical activity was usually kindled by family members:

My father was active and participated in softball for numerous years while I was growing up.... That sparked my interest in participating in softball throughout my childhood. (Isabella, formal interview)

I have a brother who was really active in sports and was a big influence on me. He taught me basic fundamental throwing and catching skills, running, those kinds of things.

(Michael, formal interview)

Two of the participants also recalled their choice of career being influenced by family members who were PE or classroom teachers:

My uncle was very active in field hockey. He was a physical education teacher and taught elementary school up to high school. He influenced me a lot in choosing my future career. (Joshua, formal interview)

Initial orientations. Those participants whose current perspectives on PE and PETE were relatively conservative were much more likely to have entered their own undergraduate PETE programs or graduate programs with coaching orientations. As revealed in the following reflective poster excerpts, key to the formation of these orientations were the high level of participation in traditional sport, the focus of their own PE teachers on extracurricular sport, and their participation in low-quality "ball rolling type of PE:"

I played basketball, volleyball, and ran track in middle and high school. ... I was very successful at all three.... Middle school PE was mostly game play with little emphasis 
on skill and high school PE was replaced with an athletic period for basketball practice. (Emily, reflective poster)

My elementary PE was free play on the playground. . . Middle school [PE] was based on sports skills with game play. .. . I didn't have to do PE in high school because I participated in varsity water polo and varsity swimming. (Madison, reflective poster)

I didn't have a PE specialist when I was in elementary school. . . . My classroom teacher was responsible for physical activity. . . It was just free play. My middle and high school PE were based on recreational play. ... G Grading was based on dressing out and participation. (Ella, reflective poster)

By contrast, those doctoral students whose current perspectives on PE and PETE were relatively liberal were much more likely to have entered their own undergraduate PETE programs with teaching orientations. Primary influences which shaped these orientations were their participation in lower level, less traditional, more informal, and less "organized" forms of sport and physical activity and the fact that they were taught "teacher driven," "high quality," and "structured" PE by "good" or "great" teachers who were "teaching-oriented and wellorganized:"

I wasn't necessarily involved in any organized sports. There were good elementary PE teachers. . . I I learned a lot from them. My high school PE teacher was great. ... He tried very hard to be a good teacher. (Olivia, formal interview)

I had an awesome elementary PE teacher and she really tried to teach different things. . . My middle school PE teacher was great. She was a lot like my elementary teacher. She would plan out different things for us to do. She really did a lot of organized lessons. (Ava, formal interview)

\section{Initial Professional Socialization}

\section{Positive Recollections}

Ten of the participants in the study were trained to teach PE within undergraduate PETE programs. Of these participants, six were "very positive" about their experiences in these programs and typically described them as "beneficial" and a "good and valuable experience." 
Their recollections indicated that these programs were similar to the types of program they now espoused. That is, they primarily reflected a combination of the behavioristic and traditional/craft orientations to teacher education. This meant that there was a heavy emphasis on learning specific technical "teaching behaviors," "planning skills," "teaching styles," and "different curriculum models" or, more generally, on gaining Shulman's (1987) pedagogical, content, pedagogical content, and curricular knowledge:

I had to write out lots of units, lots of lesson plans, and lots of yearly curriculums.... I had to prepare lessons and then teach them. It was a valuable experience for me. (Olivia, formal interview)

We did a lot of lesson plans and spent a lot of time in early field experiences.... We learned various teaching styles.... Sometimes we did practice teaching with each other in a small group. It was very helpful. We used all that stuff when we taught students. (Emily, formal interview)

Key elements in the participants' PETE programs were "well structured" "methods courses," "very helpful . . . early field experiences" which involved "teaching units in the schools in small groups," "content courses," the culminating "student teaching" practice, and, to a lesser extent, "peer teaching." In addition, participants who were positive about their PETE experience indicated that they had learned much from their cooperating teachers and had a good deal of confidence in the faculty teaching the courses because they were "specialists" in sport pedagogy, "knew a lot about teaching," were "experienced," "qualified," and "supervised" their field experiences and student teaching "closely:"

I think that the best experience was that I was teaching [within EFEs] while I was going through school [i.e., university]. So the things that I was being taught or asked to learn about [in methods courses], I was able to apply directly. So it was helpful that I was teaching while I was going through the ... program. (Sophia, formal interview)

I learned a lot and we were working with people who had a lot of experience and a lot of knowledge in teaching. They supervised and helped us and tried to make us better teachers. So it was really helpful. ... Early field experiences had a big impact on the way I wanted to teach. (Emily, reflective poster) 
The professors that taught the methodology would come around and supervise closely and have conferences. ... They had a huge impact in the way I do things right now and how I understand teaching. . . . Methods courses were organized well and really beneficial. (Joshua, formal interview)

I had field experiences during undergraduate PETE. I observed my teacher for a week and then I taught everyday for the next 7 weeks for the elementary PE. And then, I observed for a week and then taught for 8 weeks for the secondary PE. I gained a lot of knowledge in teaching from a cooperating teacher . . . It was really helpful. (Madison, formal interview)

Moreover, participants who were trained within these types of programs explained that faculty often contrasted good and poor practice and "really helped [PTs] to learn about what good PE looks like as well as what bad PE looks like." Furthermore, they recalled being "really pushed ... to learn how to do things the right way," and that "ball rollers weren't acceptable." Consequently, those that entered their programs with teaching orientations had these orientations "strengthened" and those who entered PETE with coaching orientations had them dismantled until they too possessed teaching orientations:

I entered PETE with a teaching orientation and as I continued with methods courses the teaching orientation was strengthened. . . The PETE faculty guided me in the right direction. (Olivia, reflective poster)

At the beginning of the PETE program, I was interested in coaching, but by the end I had completely changed my orientation from coaching to teaching and was fully inducted into the PETE program. (Emily, reflective poster)

Finally, it is important to note that the participants who perceived their PETE to have been a positive experience made no mention of courses in the various exercise sciences and humanities or educational foundations, such as educational psychology, sociology, and philosophy. Presumably, then, they did not regard these courses as having any effect on their perspectives or practices. Moreover, there was no mention of any kind of critical element within these participants' PETE. 


\section{Negative Recollections}

Four of the doctoral students perceived the quality of their initial PETE to have been low and, consequently, judged them as "not effective." These programs appeared to have had no theoretical or research base and included little in the way of instruction in and practice of pedagogical skills, principles, and models and “didn't have a lot of EFE opportunities.” Instead, they consisted of a series of loosely constructed "content courses." Moreover, EFEs and student teaching were "not well supervised" and there was no attempt by the faculty or graduate students teaching the courses to take on those with faulty perspectives. As a result, it appeared that the orientations with which the participants' entered these programs were largely untouched. Typical of the comments made by this group of participants on their initial PETE were the following:

The methods course I took during my undergraduate PETE, I do not think it was effective because my only memory of it was making equipment out of nothing, like making paddles out of coat hangers, and I thought that was a waste of time. (Ella, formal interview)

I didn't really learn anything. I can't recall anything. I had a chance to intern in high school and didn't like it. That's why I want to get my Ph.D . . . So the internship made me change my mind. (Ying, formal interview)

\section{Organizational Socialization}

On graduating from their undergraduate PETE programs, eight of the participants in the study moved on to teach PE in schools. Five of the participants indicated that, at this time, they had teaching orientations and three recalled being oriented to coaching. Two of the participants were employed in high schools, three in middle schools, and three in elementary schools. The cultures at these schools were mostly very "conservative" and "custodial." These cultures made life difficult for new teachers with innovative teaching orientations but served to reinforce new teachers who entered the profession with coaching orientations. Conversely, the cultures within a 
few schools were relatively liberal and innovative and so supported new teachers with teaching orientations and "new ideas." Elementary School cultures were more likely to be encouraging of new teachers with teaching orientations than those of middle and high schools.

Regardless of whether schools were relatively conservative or liberal, their key socializing agents were administrators, other PE teachers, and pupils. Participants who worked at more conservative schools recalled that all three of these countered efforts to teach high-quality PE:

The physical education department had been marginalized by the Principal and teachers [of other subjects].... We had a limited amount of equipment. ... The administrators didn't know about quality physical education. (Sophia, reflective poster)

There were three persons in the PE department. ... I participated in a required mentoring program but it didn't help at all because my mentor was a ball roller. ... There was pressure from one co-worker to "take it easy." (Olivia, reflective poster)

My first job was at an inner-city school. ... I tried to employ the sport education model to promote active class participation but the students were not very interested in ... They had never experienced sport education before. (Emily, formal interview)

The other teachers in PE departments at these more conservative schools usually had "no specific goals," a "lack of pedagogical content knowledge," and their curricula tended to be the kind of low-quality, uneducational "general multi-activity" programs described by Ennis (1999).

In congruence with Van Maanen and Schein's (1979) tactical framework, the socialization in these more conservative schools most often involved divestiture, and was variable and serial. More positively, it tended to be informal, random, and individual. To counter these predominantly negative tactics, participants with teaching orientations employed the different strategies described by Etheridge (1989) and Lacey (1977). That is, they strategically adjusted, strategically complied with, or attempted to strategically redefine practices and perspectives which existed in their schools: 
When I started my job at the school, I had a passion for teaching students. . . . I brought many new ideas and new teaching methods to the department. . . . Two co-workers were ball rollers, and they didn't care. . . I was quickly unmotivated. (Jacob, formal interview)

There were no specific goals in the PE department. . . . My colleagues made me work even harder to show students what a PE teacher is supposed to do. ... I fought against the negative influences. (Emily, formal interview)

A few participants who worked at conservative schools also recalled that they could "utilize PETE faculty whenever [they] had concerns about [their] teaching" or "call [their] co-operating teacher from ... student teaching." Further, when others, like Isabella, felt that "washout and survival mode was starting to set in ... [they] decided to enter the classroom and teach . . . health ... to get away from colleagues who were ball rollers and negative influences.”

By contrast, while the socialization of participants who taught at more liberal schools was variable, more positively it tended to be informal, disjunctive, individual, random, and involve investiture. For example, Michael explained that while "the departmental main goal was to follow the Alabama course of study as sort of a roadmap [he could carry out] any type of modifications, in terms of extra things, that [he] wanted to add." Others relayed how they "made the decisions on what was taught," described their curricula as "inclusive" and focused on "learning," and noted that they had considerable "freedom" to make curricular "decisions." Moreover, several participants who worked in liberal schools were encouraged to employ the different curriculum models that they had mastered in their training, particularly "sport education and the teaching games for understanding model."

Finally, in general, administrators, other teachers, and pupils at more liberal schools aided efforts to teach quality PE:

I had a lot of support from my administrators. . . The facilities were new and we had lots of equipment to choose from. ... I think they put me in the best situation to succeed which made my job a lot easier. (Ethan, formal interview) 
We [i.e., all the teachers in the PE department] had a meeting and prepared a curriculum together on what we needed to teach in the term.... We collaborated on a regular basis. (Joshua, formal interview)

I taught a few years at a private school and ... I tried to employ new ideas in PE classes. ... The students had enthusiasm for learning new things. (Ethan, formal interview)

\section{Secondary Professional Socialization}

Eight of the doctoral students had completed master's degrees in sport pedagogy prior to the study. The remaining four participants had studied other subject matters in their master's degree programs (i.e., sport management, foundations of education, and public administration) and so their secondary professional socialization was restricted to their doctoral work. Importantly, for the three participants who had not completed undergraduate PETE, this graduate work served as their initial professional socialization. Nine of the participants began their graduate work with teaching orientations and three with coaching orientations.

During the course of the study, it became apparent that the participants had made the decision to pursue a doctoral degree for a number of different reasons. Some explained that they wanted to be "researchers" of PE teaching and teacher education and others that they wanted to "train teachers." A small group also indicated that they were attracted more broadly to "teaching at the college level" and implied that subject matter studied was of secondary importance to this main goal. This group also appeared to view teaching university students as a natural progression and aspiration for more talented school teachers. Some of the participants also indicated that they were interested in working as PETE faculty because they perceived it as being more professionally prestigious. They also saw this career path as potentially more satisfying because they would be removed from the problems of dealing with non-supportive school administrators and non-teaching colleagues. A final group appeared to have "drifted" into their doctoral 
programs and were really "testing the waters." This group was not yet committed to seeking a position as a university PETE faculty member on graduation.

All of the participants were positive about the influence of their graduate programs on their practices and perspectives on PE teaching and PETE. As illustrated in the following data extracts this meant that those who began their graduate work with coaching orientations were "converted" so that they were now oriented to teaching and those who started their graduate programs with teaching orientations had these orientations strengthened:

I had a coaching orientation at first but moved to a teaching orientation during graduate work. . . . The PETE professors tried to help us and make us better teachers. . . The graduate program was really influential on me. (Emily, formal interview)

The reading of other researchers' articles and discussing them, going out there in the schools, and supervising undergraduate students and watching what they do and helping them out ... influenced and strengthened my perspective and practice as a physical educator. (Ethan, formal interview)

Moreover, those participants who began their graduate work with teaching orientations already well formed were more likely to espouse more liberal and progressive versions of PE teaching and PETE than those who started graduate work with coaching orientations still intact (see the sections on current practices and perspectives above).

Key elements and experiences within the graduate programs which had most influence on the participants were their "professors," "field experiences," the opportunity to teach themselves, their engagement in the undergraduate PETE program, and, to a lesser extent, the content of coursework focused on theory and research. Professors were particularly influential in terms of solidifying and "broadening" perspectives on PE teaching and PETE:

Dr. Jones has had a big impact on my perspectives as a physical education teacher. . . I've read many research articles, and then we discuss them in class. It has influenced me a lot and strengthened my knowledge of PE teaching. (Emily, formal interview) 
I think that each professor is influential depending on the area in which they are proficient. ... Each professor brings a little something different ... so I've learned little bits and pieces of maybe how to shape my experiences based on their expertise.... They all bring a little different perspective. That's a good thing. (Sophia, formal interview)

Field experiences were usually attached to master's degree courses and proved helpful because participants could observe what they had been taught:

Field experiences had a lot of impact on what I do now because when I was in the graduate program ... I went to other schools to observe, I knew more about what I was looking for, and I was looking for new ideas, so that was probably the experiences that influenced the most of how I teach. (Emily, formal interview)

Similarly, whether it was teaching within a school or teaching within the university basic PE program, participants noted that this activity gave them a chance to "practice" and "experiment" with the skills and concepts they had read about and discussed in class or observed in field experiences:

I think that the best experience was that I was teaching while I was going through the graduate program. So the things that I was being taught or asked to learn about, I was able to apply directly. So it was very helpful. (Sophia, formal interview)

Working alongside PETE professors or having full responsibility for teaching methods courses, organizing and supervising EFEs, and supervising student teachers influenced both the participants' own teaching and views on PETE:

I had a chance to go and observe [student teachers'] lessons ... how they taught and how they did skills based on curriculum. ... That provided me the opportunity to learn more about teaching skills. (Ava, formal interview)

I had to do observations [of undergraduates] and ... interventions, and so it's kind of made me think about my teaching a little bit more. The observations, and interventions, . . . to change negative behaviors toward positives, helped me a lot. (Olivia, formal interview)

I worked with the student interns when they had their whole semester out in the schools. That is where I really got to see whether our [undergraduate] methods courses and our practices have been effective or whether they have not. Those were the experiences that really influenced my teaching career as an educator. (Ella, formal interview) 
Finally, the content within coursework that the participants highlighted as influencing their practices and perspectives as PE teachers and future PETE professors in particular included "research on physical education teacher education," and "the curriculum course" because it "opened their eyes to other curriculum models." Also mentioned was "reading research articles" on "teaching physical education" because they helped in the formation of "pedagogical content knowledge." 


\section{CHAPTER IV}

\section{CONCLUSIONS}

Due to the body of research that has been produced on the occupational socialization of PE teachers, PETE faculty rarely make the mistake of assuming that all of their undergraduate charges have entered their programs because they are motivated by the prospect of teaching PE. Instead, they realize that PTs come with a variety of different backgrounds and often faulty perspectives which may well be difficult to change for the better. It is my contention that the same cannot be said of seasoned PETE faculty working with doctoral students. Although there is obviously a realization that those already doing PETE have different (but mostly sound) practices and perspectives, there is also, I think, a false idealism surrounding the training of future PETE faculty that assumes that most neophytes begin their doctoral programs fully committed and open to the most progressive ideas on PE teaching and PETE. The results of this study serve to make problematic this kind of thinking and to illustrate how the various phases of their occupational socialization shape sport pedagogy doctoral students' practices and perspectives on teaching and teacher education.

Prior to the study, I had hypothesized that most, if not all, students entering a sport pedagogy doctoral program would have been oriented to teaching from an early age. A key finding, then, was that I was wrong as this was not the case. Indeed, some participants began their initial and secondary professional socialization with coaching orientations firmly intact. Also of importance was the fact that these coaching orientations appeared to have been altered 
for the better by the time the study was conducted. The longer they remained intact, however, the more likely it was that doctoral students would espouse more conservative and traditional forms of PE and PETE and reject more liberal and progressive pedagogies and ideas.

Prior to their graduate work, the study also revealed that the pattern of socialization for the participants was similar to that of previously studied PTs and practicing teachers (e.g., see Curtner-Smith, 2009). Specifically, the influences of acculturation and organizational socialization were much more powerful than those of professional socialization although highquality PETE was effective in countering weak or moderate coaching orientations.

What was new, however, was the current study indicated that the participants' secondary professional socialization (i.e., graduate work) was relatively potent and powerful to the extent that it could overcome moderate coaching orientations that had survived to that point in a teacher/teacher educator's career. Moreover, the study suggested that this potency was primarily the result of influential faculty, a practitioner focus in master's degree programs, and engagement in undergraduate PETE.

Future research in this area might examine the extent to which the findings of the current study generalize. Of particular interest and practical use would be a focus on the types of practices and perspectives doctoral students acquire by the time of their graduation, the components that facilitate this acquisition, and the relative strengths of the various phases of socialization on these practices and perspectives. In addition, profiles of any doctoral students with coaching orientations who are not turned would be of interest. Finally, studies which follow doctoral students into the next phase of their careers as college and university PETE faculty and so examine the influences of what might be termed their secondary organizational socialization 
on their perspectives and practices and how these interact with prior socialization are obviously needed. 


\section{REFERENCES}

Curtner-Smith, M. D. (2001). The occupational socialization of a first-year physical education teacher with a teaching orientation. Sport, Education and Society, 6(1), 81-105.

Curtner-Smith, M. D. (2007). Influence of a critically oriented physical education methods course and early field experience on preservice elementary teachers' conceptions of teaching. Journal of Teaching in Physical Education, 26(1), 35-56.

Curtner-Smith, M. D. (2009). Breaking the cycle of non-teaching physical education teachers: Lessons to be learned from the occupational socialization literature. In D. L. Housner, M. W. Metzler, P. G. Schempp, \& T. J. Templin (Eds.). Historic traditions and future directions of research on teaching and teacher education in physical education (pp. 221226). Morgantown, WV: Fitness Information Technology.

Curtner-Smith, M. D., Hastie, P. A., \& Kinchin, G. D. (2008). Influence of occupational socialization on beginning teachers' interpretation and delivery of sport education. Sport Education and Society, 13(1), 97-113.

Curtner-Smith, M. D., \& Sofo, S. (2004). Influence of a critically oriented methods course and early field experience on preservice teachers' conceptions of teaching. Sport, Education and Society, 9(1), 115-142.

Ennis, C. D. (1999). Creating a culturally relevant curriculum for disengaged girls. Sport, Education and Society, 4, 31-49.

Etheridge, C. P. (1989). Strategic adjustment: How teachers move from university learnings to school-based practices. Action in Teacher Education, 11(1), 31-37.

Fernandez-Balboa, J. M. (1997). Physical education teacher preparation in the postmodern era: Toward a critical pedagogy. In J. M. Fernandez-Balboa (Ed.), Critical post-modernism in human movement, physical education and sport (pp. 121-138). Albany: State University of New York Press.

Goc Karp, G., \& Williamson, K. (1993). PETE faculty at work: The reciprocal nature of organizational structures and identity. Journal of Teaching in Physical Education, 12(4), 413-423.

Goetz, J. P., \& LeCompte, M. D. (1984). Ethnography and qualitative design in educational research. San Diego, CA: Academic Press. 
Graber, K. (1993). The emergence of faculty consensus concerning teacher education: The socialization process of creating and sustaining faculty agreement. Journal of Teaching in Physical Education, 12, 424-436.

Graham, G., \& Heimerer, E. (1981). Research on teacher effectiveness: A summary with implications for teaching. Quest, 33(1), 14-25.

Jewett, A. E. (1994). Curriculum theory and research in sport pedagogy. Sport Science Review, $3(1), 56-72$.

Lawson, H. A. (1983a). Toward a model of teacher socialization in physical education: The subjective warrant, recruitment, and teacher education (part 1). Journal of Teaching in Physical Education, 2, 3-16.

Lawson, H. A. (1983b). Toward a model of teacher socialization in physical education: Entry into schools, teachers' role orientations, and longevity in teaching (part 2). Journal of Teaching in Physical Education, 3, 3-15.

Lacey, C. (1977). The socialization of teachers. London: Methuen.

Lortie, D. (1975). Schoolteacher: A sociological study. Chicago: University of Chicago Press.

Mitchell, M. F. (1993). Linking teacher educators, knowledge, and the quality of practice in schools. Journal of Teaching in Physical Education, 12, 399-412.

Patton, M. Q. (1990). Qualitative evaluation and research methods (2nd ed.). Newbury Park, CA: Sage Publications.

Schempp, P. G., \& Graber, K. C. (1992). Teacher socialization from a dialectical perspective: Pretraining through induction. Journal of Teaching in Physical Education, 11, 329-348.

Shulman, L. S. (1987). Knowledge and teaching: Foundations of the new reform. Harvard Educational Review, 57(1), 1-22.

Silverman S. (1991). Research on teaching in physical education. Research Quarterly for Exercise and Sport, 62, 352-365.

Stroot, S. (Ed.) (1993). Socialization into physical education [Monograph]. Journal of Teaching in Physical Education, 12. 337-466.

Templin, T. J., \& Schempp, P. G. (Eds.) (1989). Socialization into physical education: Learning to teach. Indianapolis, IN: Benchmark Press.

Van Maanen, J. \& Schein, E. H. (1979). Toward a theory of organizational socialization. In B. Staw (Ed.), Research in organizational behavior (Vol. 1, pp. 209-261). Greenwich, CT: JAI Press. 
Zeichner, K. M. (1983). Alternative paradigms of teacher education. Journal of Teacher Education, 34, 3-9.

Zeichner, K. M., \& Tabachnik, B. R. (1981). Are the effects of university teacher education "washed out" by school experience? Journal of Teacher Education, 32, 3-9.

Zeichner, K. M., \& Tabachnik, B. R. (1983, April). Teacher perspectives in the face of the institutional press. Paper presented at the annual meeting of the AERA, Montreal, ON, Canada. 
Appendix A

Interview Script 
1. Background Information (multiple prompts allowed)

- What is your age?

- Where was the place of your birth?

- What is your ethnic origin?

- What is your sex?

- At what stage are you in your doctoral program?

2. Acculturation (multiple prompts allowed)

- Were your parents/guardians, siblings or any close relatives active or inactive in sport or physical activity during your childhood and adolescence? Please elaborate.

- Would you describe yourself as active or inactive during your childhood and adolescence? Please elaborate.

- If you were an active child and/or adolescent, in which physical activities and sports did you take part? At what level did you take part in any formally organized sport?

- Describe the PE programs you experienced at the elementary, middle, and high schools you attended.

- Describe the of extracurricular sport and physical activity programs you experienced at the schools you attended.

- Describe the PE teachers who taught you curricular PE.

- Describe the teachers/coaches who worked with you during any extracurricular sport or physical activity in which you participated.

- Describe the coaches who taught you sport or physical activity outside the school setting during your childhood and adolescence.

- Did you participate in sport and physical activity during your undergraduate education? If so, please describe.

- Do you currently participate in or coach any sport or physical activity? If yes, please elaborate.

- Why did you decide to become a PE teacher?

3. Primary Professional Socialization (multiple prompts allowed)

- Describe the professors who trained you to teach PE during your PETE program.

- Were you taught by professors who specialized sport pedagogy?

- To your knowledge, did any of the professors who trained you to teach PE coach university sports teams? If yes, please elaborate.

- Describe any methods classes which you took during your PETE.

- Describe any EFEs, internships, or student teaching practices which were part of your PETE. Were these supervised by the same professors that taught your methods classes?

- When you graduated from your PETE program what sort of position were you interested in acquiring what were your objectives as a new PE teacher?

4. Organizational Socialization (multiple prompts allowed)

- Describe the school(s) in which you taught/teach. How many pupils attended/attend/ the school(s) and what were/are their backgrounds? What type of catchment area did/do/does the school(s) have? 
- Describe the PE Departments for the school(s) you taught/teach in. How many teachers were/are there in the department? What were/are their approximate ages? Approximately how long had/have they been at the school? What kind of facilities and equipment did/do you have? What were/are the department's main goals?

- Were there any other newly qualified PE teachers or teachers of other subjects employed at the first school at which you were hired? If yes, how much contact did/do you have with them?

- Were you assigned an official mentor or did you have an unofficial mentor within the first school when you were a beginning teacher? If yes, please describe his/her influence on your teaching.

- Were you given specific goals to achieve as a newly qualified teacher? If yes, were these listed in any order? Were you given a set time period in which to achieve these goals?

- Describe PE curriculum/curricula and extracurricular sports program(s) of the schools you taught/teach in.

- Who made/makes the decisions on what was/is taught in the PE department(s) of the school(s) you taught/teach in?

- Who made/makes the decisions on how content was/is taught in the PE department(s) of the schools you taught/teach in?

- How much input did/do you have on content taught and curriculum models employed in the school(s) you taught/teach in? Did/do your colleagues embrace any new ideas you brought/bring to the department?

4. Secondary Professional Socialization (multiple prompts allowed) Master's program

- Did you do a master's degree in sport pedagogy? If yes:

- Were the professors who taught the courses in your master's program specialists in sport pedagogy? Were they active researchers in sport pedagogy? Did they train undergraduate students to teach PE?

- Which persons from within your master's program (if any) influenced your perspectives and practices as a physical education teacher?

- Which persons from within your master's program (if any) influenced your perspectives and practices as a physical education teacher educator?

- Which courses from within your master's program (if any) influenced your perspectives and practices as a physical education teacher?

- Which courses from within your master's program (if any) influenced your perspectives and practices as a physical education teacher educator?

- Which other experiences from within your master's program (if any) influenced your perspectives and practices as a physical education teacher?

- Which other experiences from within your master's program (if any) influenced your perspectives and practices as a physical education teacher educator? 


\section{Doctoral program}

- Are the professors who teach the courses in your doctoral program specialists in sport pedagogy? Are they active researchers in sport pedagogy? Do they train undergraduate students to teach PE?

- Which persons from within your doctoral program (if any) have influenced your perspectives and practices as a physical education teacher?

- Which persons from within your doctoral program (if any) have influenced your perspectives and practices as a physical education teacher educator?

- Which courses from within your doctoral program (if any) have influenced your perspectives and practices as a physical education teacher?

- Which courses from within your doctoral program (if any) have influenced your perspectives and practices as a physical education teacher educator?

- Which other experiences from within your doctoral program (if any) have influenced your perspectives and practices as a physical education teacher?

- Which other experiences from within your doctoral program (if any) have influenced your perspectives and practices as a physical education teacher educator?

- When you graduate what kind of position do you hope to acquire?

- What are the main perspectives and practices you hope your future undergraduate students acquire? 